\title{
Workshop Pelatihan Learning Management System Secara Online Dengan Menggunakan Google Classroom Untuk Guru SMAK St. Albertus, Malang.
}

\author{
Rizky Basatha $^{1^{*}}$, David Saputra Octadianto Soedargo ${ }^{2}$, Alexander Wirapraja ${ }^{3}$ \\ ${ }^{1 *}, 2,{ }^{3}$ Program Studi Sistem Informasi, Institut Informatika Indonesia, Surabaya, Jawa Timur \\ Email: ${ }^{1}$ rizky@ikado.ac.id , ${ }^{2}$ david@ikado.ac.id, ${ }^{3}$ awirapraja85@gmail.com
}

(Naskah masuk: 19 April 2021, direvisi: 04 Mei 2021, diterima: 20 Mei 2021)

\begin{abstract}
Abstrak
Proses pembelajaran adalah salah satu aspek yang terdampak perkembangan teknologi, seorang guru dituntut tidak hanya mampu menyampaikan materi dengan baik tapi sekaligus juga menjadi fasilitator yang baik dalam menyampaikan materi sebagai bentuk proses pembejaran yang efektif dan efisien, kendala dari permasalahan pembelajaran konvensional dapat diatasi dengan menyediakan sarana pembelajaran yang baik dan fleksibel menggunakan aplikasi berbasis Learning Management System (LMS), dalam proses pengabdian masyarakat dilakukan proses pelatihan kepada para guru SMA dari SMAK St. Albertus Malang dan fasilitator dari pelatihan ini adalah dosen Institut Informatika Indonesia, pada pelatihan ini menggunakan metode interaktif dan praktek langsung dengan menggunakan salah satu aplikasi LMS yaitu Google Classroom. Aplikasi ini dipilih karena mudah digunakan dan telah dikenal secara umum, selain pelatihan dengan menggunakan Google Classroom, para peserta juga dibekali dengan pengetahuan umum tentang fitur dan fasilitas google lainnya, hasil dari pelatihan ini adalah adanya penambahan wawasan baru yang dapat digunakan guru untuk meningkatkan proses pembelajaran dikelas dan meningkatkan interaksi antara para guru dan murid sehingga kualitas pembelajaran pada kelas tersebut menjadi lebih baik.
\end{abstract}

Kata Kunci: LMS, Google Classroom, SMA, Pelatihan

\section{Online Learning Management System Workshop and Training Using Google Classroom for Teachers at SMAK St. Albertus Malang}

\begin{abstract}
The learning process is one of the aspects affected by technological developments, a teacher is required not only to be able to convey material well but also to be a good facilitator in delivering material as a form of an effective and efficient pursuit process, obstacles from conventional learning problems can be overcome by providing facilities. good and flexible learning using a Learning Management System (LMS) based application, in the community service process a training process was carried out for high school teachers from SMAK St. Albertus Malang and the facilitator of this training are lecturers from the Institut Informatika Indonesia (IKADO) Surabaya. This training uses interactive methods and hands-on practice using one of the LMS applications, namely Google Classroom. This application was chosen because it is easy to use and has been generally known, in addition to training using Google Classroom, the participants are also equipped with general knowledge about other Google features and facilities, the result of this training is the addition of new insights that teachers can use to improve the learning process class and increase the interaction between teachers and students so that the quality of learning in the classroom is better..
\end{abstract}

Keywords: LMS, Google Classroom, High School, Workshop 


\section{PENDAHULUAN}

Di era industri 4.0 sekarang ini, banyak usaha jasa yang memanfaatkan teknologi cyber dan teknologi otomatisasi. Hal ini tentunya dapat menambah nilai efisiensi pada suatu lingkungan kerja dimana manajemen waktu dianggap sebagai sesuatu yang vital dan sangat dibutuhkan. Contoh konkrit yang dapat diambil dari pemanfaatan teknologi pada bidang usaha jasa edukasi atau Pendidikan adalah proses pembukuan yang kini sudah dapat dengan mudah diakses oleh siapa saja dan kapan saja.

Didalam dunia Pendidikan yang secara konvensional para pengajar dituntut pula untuk melakukan pengembangan dalam metode pembelajaran untuk mendukung proses penyamapaian materi kepada murid, seorang guru terkadang memiliki beberapa kekurangan dan kendala dalam mempersiapkan pembelajaran yang baik, beberapa faktor yang menjadi hambatan antara lain adalah faktor waktu, kehadiran dan presensi guru dan murid, pembuatan dokumentasi, evaluasi dan proses pelaporan data. Dalam proses belajar mengajar guru harus dapat menyiapkan waktu yang sudah ditentukan dan terkadang kurang fleksibel karena adanya keterbatasan waktu. Kehadiran dari guru serta murid sangat dibutuhkan agar kegiatan belajar mengajar dapat berlangsung. Dokumentasi masih berupa buku dan untuk menghasilkan suatu laporan membutuhkan tenaga kerja manual yang memproses dokumentasi tersebut.

SMAK St. Albertus Malang merupakan Sekolah Menengah Atas yang berprestasi dalam bidang akademik maupun dalam bidang non akademik. Dalam bidang non akademik, siswa dan siswi dari SMAK St. Albertus aktif dalam pelatihan maupun dalam rangka menjadi kontingen daerah maupun Indonesia yang tentu saja mengharumkan nama bangsa dan juga nama sekolah tempat para atlet belajar. Hal ini tentu saja menjadi sebuah masalah mengingat pengiriman kontingen untuk mengikuti pertandingan dengan skala nasional dan internasional membutuhkan waktu yang tidak sedikit. Belum lagi dengan adanya pelatihan baik rutin maupun pelatihan intesif menjelang dimulainya acara nasional maupun internasional. Hal ini tentu saja menjadi perhatian bagi guruguru maupun para petinggi di SMAK St. Albertus Malang.

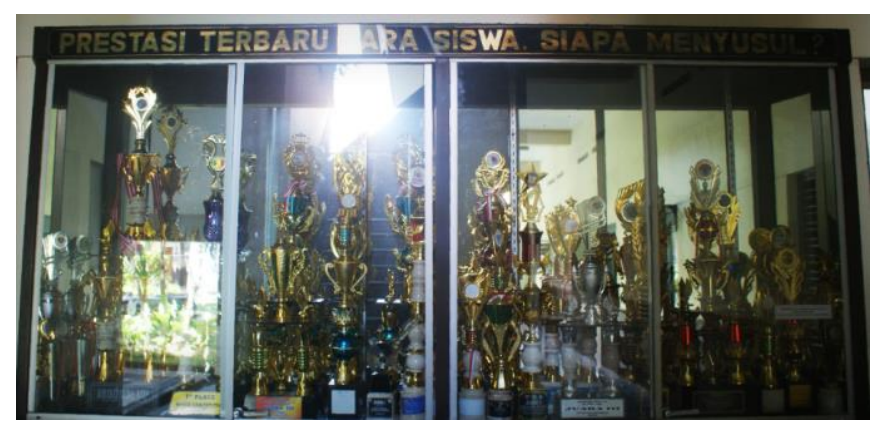

Gambar 1. Koleksi Prestasi Baru SMAK St. Albertus Malang

Dengan adanya Learning Management System (LMS) dapat membantu dalam administrasi, dokumentasi, pelacakan, pelaporan, dan penyampaian pendidikan yang lebih efisien dan praktis. Secara definisi LMS sendiri adalah sistem manajemen pembelajaran yang dikemas dengan menggunakan teknologi sehingga dapat digunakan sebagai media pendukung proses akademis[1]. Dengan mengimplementasikan LMS ke sekolahsekolah dapat meningkatkan efisiensi proses belajar mengajar. Guru dan murid dapat mengatur jadwal belajar mengajar secara online sehingga lebih fleksibel. Guru dan murid tidak dibutuhkan kehadirannya dimana guru tidak perlu datang ke kelas untuk memberikan tugas tetapi cukup menyampaikannya melalui dunia maya, kemudian murid mengerjakan tugas tanpa mengumpulkan langsung kepada guru tetapi melalui dunia maya. Tugas yang dikumpulkan secara online dapat disimpan bahkan dapat menghasilkan informasi laporan nilai yang dihasilkan dari tugas tersebut sehingga guru tidak perlu waktu dan tenaga untuk menilai tugas tersebut. Dapat disimpulkan bahwa pembelajaran melalui dunia maya atau internet dengan mengimplementasikan LMS dapat bermanfaat bagi pembelajaran.

Google Classroom meurpakan salah satu bentuk dari Learning Management System, yang digunakan oleh guru dan siswa dalam rangka mempermudah proses pembelajaran, aplikasi ini diperkenalkan oleh Google ditahun 2014 dengan membawa konsep pembelajaran tanpa terikat pada ruang dan waktu [2]. Beberapa menu utama dalam Google Classroom adalah:

1. menu stream merupakan fasilitas Google Classroom untuk membuat info akademis seperti pengumuman, kolom diskusi antara guru dan murid, kumpulan dari materi, tugas dan topik pembelajaran.

2. menu classwork adalah menu yang digunakan oleh guru untuk membuat latihan, tugas, quiz dan melakukan evaluasi terhadap peserta didik mereka.

3. menu people adalah menu dimana guru atau pengguna dapat mengundang peserta lain baik antar guru ataupun siswa untuk mengikuti proses pembelajaran yang ada.

Google Classroom dipilih karena merupakan platform yang paling banyak digunakan untuk melakukan pembelajaran jarak jauh (PJJ) menurut survei dari Lembaga Arus Survei Indonesia dikutip oleh kompas.com [3] yang dilakukan pada oktober 2020 pada 34 provinsi di Indonesia menyebutkan bahwa pengguna sebesar $26.1 \%$ memilih menggunakan Google Classroom dalam melakukan PJJ, disusul oleh Ruang Guru sebesar (17.1\%) dan Ruang Belajar sebesar (15.2 \%)

\section{METODE KEGIATAN}

Untuk mencapai perubahan dan pengetahuan dan pemahaman kepada guru-guru SMAK St. Albertus Malang maka perlu dilakukan beberapa tahapan sebagai berikut:

a. Perencanaan

\section{Melakukan Survei}

Melakukan survei ke SMAK St. Albertus Malang untuk melihat bagaimana kesiapan infrastruktur dan sumber daya manusia di sekolah tersebut. Dari hasil survei dan pengamatan secara langsung dilapangan ditemukan bahwa sebenarnya SMAK St. Albertus Malang telah memiliki kesiapan akan 
infrastruktur dan laboratorium penunjang pembelajaran berbasis teknologi informasi yang baik, dimana dapat dilihat bahwasanya dari kecepatan internet yang tergolong tinggi dan jumlah komputer yang banyak menyesuaikan dengan kuota siswa yang dimilikinya. Sedangkan dari sisi sumber daya manusia khususnya guru dan staf pengajar telah banyak yang dapat menggunakan aplikasi google drive dan beberapa fitur aplikasi google yang lainnya.

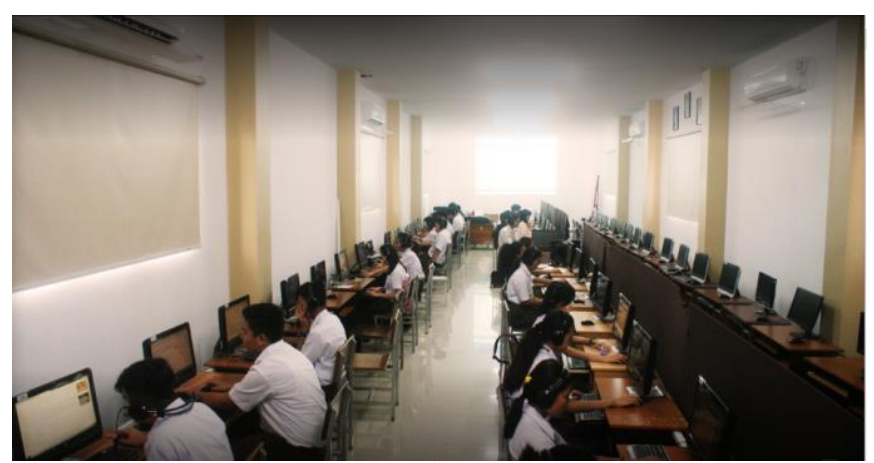

Gambar 2. Lab Komputer SMAK St. Albertus Malang

\section{Pemberian Angket}

Angket merupakan salah satu teknik dalam mendapatkan data primer yang akan digunakan untuk melihat evaluasi dari proses pelatihan yang telah dilakukan [4], secara khusus kepada para guru dari SMAK St. Albertus Malang. Proses memberikan angket kepada guru-guru di SMAK St. Albertus Malang dilakukan untuk mengukur mengenai seberapa jauh guru-guru SMA tersebut mengenal dan memahami penggunaan Google Classroom. Dari hasil angket diketahui bahwa $10 \%$ pernah mencoba menggunakan Google Classroom, $70 \%$ pernah menggunakan aplikasi Google lain selain Google Classroom, dan 20\% lainnya merasa belum pernah menggunakan aplikasi Google lainnya.

\section{b. Pelaksanaan Workshop}

1. Pembuatan Panduan

Panduan untuk mengenal dan menggunakan Google Classroom dibuat berdasarkan akun yang dimiliki oleh penulis. Yaitu menggunakan akun Gsuite milik Institut Informatika Indonesia. Di Institut Informatika Indonesia semua pegawai memiliki email dengan ekstensi ikado.ac.id yang merupakan bagian dari GSuite. Dengan adanya GSuite maka penggunaan Google Classroom dan aplikasi Google lainnya menjadi tidak berbatas.

\section{Pembagian Area Gerak Instruktur}

Para instruktur diberikan tugas untuk memahami panduan penggunaan dari Google Classroom agar nantinya mampu membimbing peserta dengan baik. Dan tidak lupa diberikan instruksi bahwasannya instruktur agar menyebar, supaya apabila peserta workshop memiliki pertanyaaan dapat segera di lakukan pembimbingan lebih lanjut.

\section{Pembicara dan Operator}

Pembicara dan Operator dalam hal ini adalah para dosen dari institut informatika indonesia akan melakukan interaksi secara interaktif dan langsung berupa latihan dan penyesuaian yang bertujuan agar terciptanya koreografi yang baik antara fasilitastor dan peserta dalam pelaksanaan workshop. Hal ini tak terlepas bahwa dalam prosesnya pembicara harus selalu berpindah dari satu peserta kepada peserta lainnya sambil menjelaskan supaya peserta merasa menjadi bagian dalam workshop tersebut.

\section{c. Evaluasi}

\section{Evaluasi Pelatihan}

Tim melakukan proses pengamatan terhadap pelatihan yang telah dilakukan dengan cara menanyakan dan berdiskusi secara langsung kepada peserta untuk mengetahui apakah seluruh peserta dapat memahami dan menggunakan aplikasi Google Classroom dengan baik atau belum dan memastikan pula apakah seluruh guru sudah dapat menggunakan aplikasi tersebut dengan lancar.

\section{PELAKSANAAN KEGIATAN}

Sesuai dengan hasil survey dan kesepakatan Institut Informatika Indonesia dengan pihak SMAK. St. Albertus, kegiatan workshop pembelajaran dan pelatihan Learning Management System menggunakan Google Classroom ini dilaksanakan selama satu (1) hari yaitu pada tanggal 26 September 2019 dengan durasi kegiatan kurang lebih 2,5 jam.

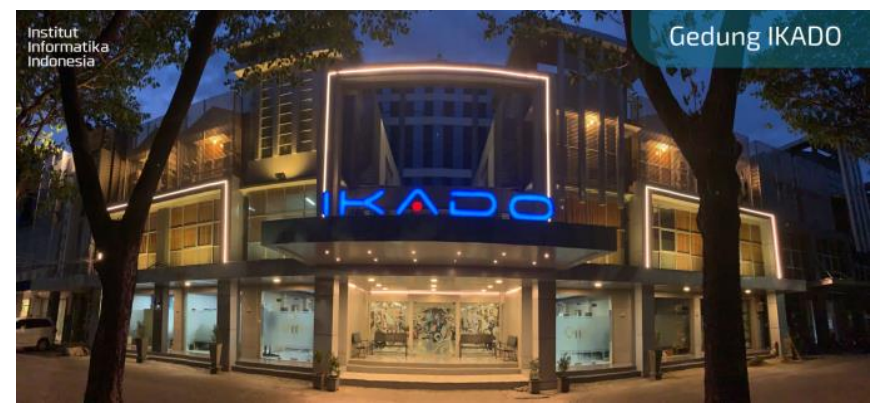

Gambar 3. Institut Informatika Indonesia

Untuk pelaksanaan kegiatan workshop bertempat di lingkungan SMAK St. Albertus Malang.

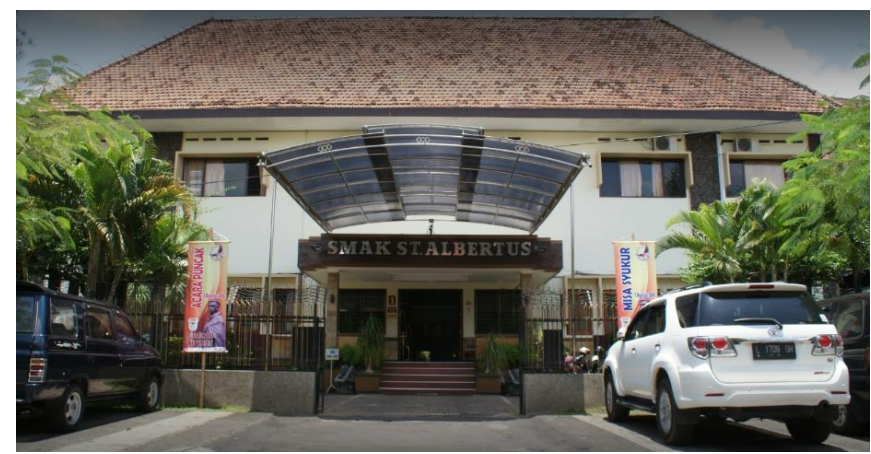

Gambar 4. SMAK St. Albertus Malang

Jumlah peserta yang mengikuti pelatihan terdiri dari kurang lebih sekitar 40 guru dilayani oleh beberapa dosen 
IKADO sebagai fasilitator dan instruktur workshop. Guru di kelas selain bertindak sebagai peserta workshop, ternyata dapat juga berperan dalam membantu jalannya kegiatan workshop dengan berpartisipasi secara aktif membantu proses pelatihan tersebut.

Kegiatan diawali dari pembagian dokumen tutorial dan panduan yang telah disiapkan sebelumnya. Beberapa guru yang sebelumnya tidak memiliki atau lupa terhadap kata sandi Gmail yang dimilikinya maka akan dibimbing untuk membuat akun gmail yang baru. Hal ini tentu saja dilakukan guna mempersingkat waktu dan mempercepat proses persiapan. Apabila mencari sandi atau mengingat sandi maka akan memakan waktu yang tidak sedikit, setelah semua memiliki akun Google yang aktif maka tahapan selanjutrnya adalah para guru akan dikenalkan dari berbagai fitur-fitur dan fungsi yang ada pada tampilan menu Google Classroom yang nantinya diharapkan dapat membantu para guru dalam mempermudah jalannya penggunaan Google Classroom dalam proses belajar mengajar dikelas. kegiatan pengenalan diawali dengan mengenalkan bagaimana cara menggunakan Google Mail (Gmail) bagi beberapa guru yang belum paham menggunakan Gmail. Lalu diteruskan dengan penjelasan mengenai fitur penyimpanan berbasis cloud yang dimiliki google yaitu Google Drive dan bagaimana cara menggunakan Gdrive. Lalu dilanjutkan dengan pengenalan Google Meet / Google Hangout dan bagaimana cara menggunakan aplikasi tatap muka secara online tersebut.

Selama workshop berlangsung, guru dikenalkan dengan apa yang disebut dengan Learning Management System (LMS) dan beserta jenis-jenis aplikasi LMS yang tersedia dan aplikasi apa saja yang dapat digunakan sebagai bagian dari pemanfaatan LMS tersebut. Para guru juga dibekali dengan perbandingan setiap aplikasi LMS dan diberitahukan serta dijelaskan apa saja kelebihan dan kekurangannya. Pada sesi ini para guru secara aktif bertanya dan menilai mengenai perbandingan antar LMS karena sebagian dari guru telah pernah menggunakan aplikasi LMS dari provider lain dan telah menjadi kebiasaan mereka. Setelah guru-guru diberitahukan tentang berbagai LMS maka akan dilanjutkan oleh sesi berikutnya, yaitu sesi penggunaan Google Classroom. Selanjutnya para guru akan dikenalkan dengan salah satu produk LMS yaitu aplikasi Google Classroom. Satu Dosen bertugas sebagai pemateri dan presentator, sedangkan satu Dosen akan membantu guru jika kebingungan selama proses workshop berlangsung.

Pada saat pengenalan Google Classroom, pertama-tama diajarkan cara untuk membuat suatu kelas baru. Lalu link dari kelas tersebut dapat di bagikan kepada siswa melalui SMS, Aplikasi WhatsApp, maupun Gmail. Setelah membuat kelas, para guru diajarkan bagaimana cara membuat sesi kelas. Dimana di setiap sesi kelas, guru dapat memberikan penjelasan, slide, maupun video tutorial yang dapat dimasukkan ke dalam kelas tersebut. Siswa dapat berinteraksi dengan guru menggunakan fitur chat di dalam sesi tersebut. Apabila dirasa perlu, guru dapat langsung membuat sesi tatap muka menggunakan aplikasi Meet yang sudah terintegrasi dengan Google Classroom sehingga siswa dapat langsung bergabung dan melakukan kelas daring melalui aplikasi Meet tersebut. Apabila ada tugas di dalam kelas, para guru telah diajarkan bagaimana cara memberikan tugas di Google Classrom beserta juga waktu pengerjaan hingga waktu pengumpulan. Apabila guru ingin memberikan kuis, guru telah diajarkan bagaimana membuat dan mengatur kuis yang diberikan dalam bentuk Google Form. Selanjutnya guru juga diajarkan bagaimana jalannya proses yang akan dijalani siswa siswa dalam mendapatkan informasi dari kelas yang telah dibuat.

Kegiatan pelatihan ini diakhiri dengan melaksanakan praktik langsung dari setiap guru mulai dari proses pembuatan kelas serta simulasi mencoba menjadi siswa yang masuk ke kelas yang dibuat oleh guru lainnya. Tentu saja hal ini ditujukan agar guru dapat mengetahui dengan jelas sudut pandang penggunaan oleh siswa yang diharapkan akan berguna untuk membantu para guru dalam meningkatkan konten materi pembelajaran yang akan diberikan oleh guru kepada para murid pada sesi kelas nantinya dan dijuga diharapkan menjadi model interaksi dua arah antara guru dan murid agar proses pembelajar menjadi semakin lebih efektif.

Selama pelaksanaan kegiatan, tidak didapatkan kendala yang berarti. Para guru SMAK St. Albertus dapat mengikuti kegiatan dengan baik. Para guru juga sangat antusias dengan Learning Management System (LMS) Google Classroom. Selain itu interaksi antara guru dengan guru lainnya dalam proses praktik dapat terlihat bahwa mereka senang mendapatkan metode belajar mengajar yang lebih efisien. Akan tetapi ada sedikit kendala terkait keterbatasan ilmu teknologi dari guru terutama guru yang sudah lanjut usia dimana belum menguasai media komputer dengan baik. Kendala menyebabkan lambatnya proses mencerna materi yang diberikan kepada guru tersebut. Hal ini dapat teratasi dengan adanya inisiatif dari guru lain yang membantu mengajarkan guru lanjut usia untuk dapat mencerna dan menggunakan media komputer. Selain itu ada kendala kecil yaitu posisi denah ruang workshop yang tidak nyaman. Hal ini mempersulit ruang gerak presentator untuk mengawasi peserta workshop serta mempersulit peserta workhop untuk menyimak materi yang disampaikan. Akan tetapi kendala ini dapat diatasi dengan inisiatif masing-masing presentator atau Dosen IKADO untuk bergerak ke peserta workshop atau guru yang kebingungan dalam mencerna materi.

\section{KESIMPULAN}

Kegiatan ini dapat dilakukan secara berkelanjutan dengan topik yang sama yaitu Learning Management System (LMS) akan tetapi dengan materi yang lebih lanjut dan juga dengan menambah peserta kegiatan yaitu murid-murid. Murid-murid juga perlu diedukasi cara-cara dalam penggunaan LMS agar mereka menjadi lebih mudah menggunakan LMS sebagai bagian dari fasilitas sarana belajar mengajar mereka.

\section{REFERENSI}

[1] I. F. Alifiyanti, F. H. Afifah, and N. Ramadoan, "PEMANFAATAN LEARNING MANAGEMENT SYSTEM ( LMS ) BERBASIS EDMODO MATERI FLUIDA DINAMIS UNTUK," in Prosiding SNFA 
(Seminar Nasional Fisika dan Aplikasinya), 2018, no. 1, pp. 155-162.

[2] R. Ramadhani et al., Platform Asesmen untuk Pembelajaran Daring: Teori \& Praktik, 1st ed., vol. 53, no. 9. Medan: Yayasan Kita Menulis, 2020.

[3] I. Kamil, "Survei: Google Classroom Jadi Platform Belajar Paling Sering Digunakan Saat PJJ," Kompas.com, 2020. https://nasional.kompas.com/read/2020/10/16/18264 341/survei-google-classroom-jadi-platform-belajar- paling-sering-digunakan-saat?page $=$ all.

[4] G. V. D. Matindas., A. Golung., and R. Paputungan., "Pemanfaatan Katalog Sebagai Sarana Temu Kembali Informasi Di Upt Perpustakaan Oleh Mahasiswa Universitas Samratulangi Manado.," Acta Diurna Komun., vol. 7, no. 3, 2018, [Online]. Available:

https://ejournal.unsrat.ac.id/index.php/actadiurnako munikasi/article/view/19969. 